\title{
Enzymatic Biotransformation of Ginsenoside Rb1 and Gypenoside XVII into Ginsenosides Rd and F2 by Recombinant $\beta$-glucosidase from Flavobacterium johnsoniae
}

\author{
Hao Hong ${ }^{1,2}$, Chang-Hao Cui ${ }^{1,3}$, Jin-Kwang Kim', Feng-Xie Jin², Sun-Chang Kim ${ }^{1,3}$, and Wan-Taek Im $^{1 *}$ \\ ${ }^{1}$ KAIST Institute for Biocentury, Korea Advanced Institute of Science and Technology, Daejeon 305-701, Korea \\ ${ }^{2}$ College of Biotechnology, Dalian Polytechnic University, Dalian 116034, China \\ ${ }^{3}$ Department of Biological Sciences, Korea Advanced Institute of Science and Technology, Daejeon 305-701, Korea
}

This study focused on the enzymatic biotransformation of the major ginsenoside $\mathrm{Rb} 1$ into $\mathrm{Rd}$ for the mass production of minor ginsenosides using a novel recombinant $\beta$-glucosidase from Flavobacterium johnsoniae. The gene (bglF3) consisting of 2,235 bp (744 amino acid residues) was cloned and the recombinant enzyme overexpressed in Escherichia coli BL21(DE3) was characterized. This enzyme could transform ginsenoside $\mathrm{Rb}_{1}$ and gypenoside XVII to the ginsenosides Rd and F2, respectively. The glutathione S-transferase (GST) fused BglF3 was purified with GST-bind agarose resin and characterized. The kinetic parameters for $\beta$-glucosidase had apparent $K_{m}$ values of $0.91 \pm 0.02$ and $2.84 \pm 0.05 \mathrm{mM}$ and $V_{\text {max }}$ values of $5.75 \pm 0.12$ and $0.71 \pm 0.01 \mu \mathrm{mol} \cdot \mathrm{min}^{-1} \cdot \mathrm{mg}$ of protein ${ }^{-1}$ against $p$-nitrophenyl- $\beta$-D-glucopyranoside and $\mathrm{Rb} 1$, respectively. At optimal conditions of $\mathrm{pH} 6.0$ and $37^{\circ} \mathrm{C}, \mathrm{BglF} 3$ could only hydrolyze the outer glucose moiety of ginsenoside Rb1 and gypenoside XVII at the C-20 position of aglycon into ginsenosides Rd and F2, respectively. These results indicate that the recombinant BglF3 could be useful for the mass production of ginsenosides Rd and F2 in the pharmaceutical or cosmetic industry.

Keywords: Panax ginseng, Biotransformation, $\beta$-glucosidase, Ginsenoside F2, Flavobacterium johnsoniae

\section{INTRODUCTION}

Ginseng (Panax ginseng Meyer) has been used as a celebrated traditional herbal medicine to cure diseases and promote health in the Orient for thousands of years $[1,2]$. Ginsenosides can be categorized into the tetracyclic triterpenoid saponins, including protopanaxadiol (PPD) and protopanaxatriol, and the pentacyclic triterpenoid saponins. The PPD-type ginsenosides are further classified by the position and number of sugar moieties attached by a glycosidic bond to the aglycon at positions $\mathrm{C}-3$ and C-20 [3]. After oral intake of ginseng, the major ginsenosides are hydrolyzed through human intestinal digestion

(cc) This is an Open Access article distributed under the terms of the Creative Commons Attribution Non-Commercial License (http://creativecommons.org/licenses/by-nc/3.0/) which permits unrestricted non-commercial use, distribution, and reproduction in any medium, provided the original work is properly cited. into the more active minor ginsenosides, which are easily absorbed. For instance, ginsenoside $\mathrm{Rb} 1$ is converted to ginsenosides Rd, F2, compound $\mathrm{K}$, and aglycon by intestinal microflora [4-6]. Therefore, converting the major ginsenosides, which account for more than $80 \%$ of the total ginsenosides, to highly active minor ginsenosides has much significance for the pharmaceutical industry.

Ginsenosides, the major active constituents of ginseng, have various biological and pharmacological activities, including anti-cancer effects [7], anti-inflammatory activity [8], and neuro-protective effects [9]. Ginsen-

Received 07 Mar. 2012, Revised 20 Jul. 2012, Accepted 20 Jul. 2012

*Corresponding author

E-mail: wandra@kaist.ac.kr

Tel: +82-42-350-4451, Fax: +82-42-350-4450 
osides Rd and F2 have several pharmaceutical functions such as anti-tumor and anti-cancer effects, curing atherosclerosis, neuro-protective effects [10-13], and so on. The minor ginsenosides can be produced by hydrolyzing sugar moieties from the major ginsenosides [14]. To date, several methods to produce pure ginsenosides such as heating, acid treatment, and enzymatic methods have been developed. The enzymatic methods are considered as the most promising approach with advantages of fewer byproducts, superior environmental protection, and better stereo-specificity [15]. In particular, the purified recombinant enzymes exhibit higher selectivity and efficiency than those isolated and purified from cultured microorganisms [16].

In this study, we report the cloning of a new gene encoding ginsenoside-hydrolyzing $\beta$-glucosidase (BglF3) from Flavobacterium johnsoniae, followed by expression in Escherichia coli and characterization of $\beta$-glucosidase (BglF3). BglF3 belongs to glycoside hydrolase family 3, and the recombinant enzyme hydrolyzed only the outer glucose moiety at the $\mathrm{C}-20$ position of ginsenoside $\mathrm{Rb} 1$ and gypenoside XVII, which are effectively converted to ginsenosides $\mathrm{Rd}$ and $\mathrm{F} 2$, respectively.

\section{MATERIALS AND METHODS}

\section{Chemicals}

Ginsenosides Rb1, Rb2, Rc, Rd, Re, Rg1, Rg3(S), F2, and C-K were purchased from Nanjing Zelang Medical Technology Co., Ltd. (Nanjing, China) and gypenoside XVII was obtained by our group as described by An et al. [17]. All the chemicals used in this study were at least analytical reagent grade, and the sources are noted individually in the methods section.

\section{Bacterial strains, vectors, and media}

F. johnsoniae KACC $11414^{\mathrm{T}}$, used as a source for cloning of $\beta$-glucosidase gene, was cultured on R2A agar (BD, Sparks, MD, USA) under an aerobic condition at $30^{\circ}$ C. E. coli BL21 (DE3) and pGEX 4T-1 plasmid (GE Healthcare, Waukesha, WI, USA) for gene cloning and expression were cultured in a Luria-Bertani (LB) medium with ampicillin (100 mg/L).

\section{Cloning, expression, and purification of recombi- nant BglF3}

Genomic DNA of F. johnsoniae KACC $11414^{\mathrm{T}}$ was extracted by using a genomic DNA extraction kit (Solgent, Daejeon, Korea). The gene, termed bglF3, encoding $\beta$-glucosidase (GenBank accession number
ABQ03809) was amplified by polymerase chain reaction (PCR) with $P f u$ DNA polymerase (Solgent) using the following primers (with BamHI and XhoI restriction sites in boldface): $b g l F 3 F$ (5'-CGGGATCCAAAAACAAAATGATATACCTTTCTGC-3') and $b g l F 3 R$ (5'-CCCCTCGAGTTATTTAATTGTGAAGTTAATTTCC-3'). The amplified fragment was digested with BamHI and XhoI and then inserted to the pGEX 4T-1 vector to generate a glutathione S-transferase (GST)-bglF3 gene fusion. E. coli BL21 (DE3), transformed with recombinant pGEX-bglF3, was grown in LB-ampicillin medium at $37^{\circ} \mathrm{C}$ until the culture reached an $\mathrm{OD}_{600}$ of 0.6 , at which point protein expression was induced by adding $0.1 \mathrm{mM}$ isopropyl- $\beta$-D-thiogalactopyranoside (IPTG). Bacteria were incubated additionally for $24 \mathrm{~h}$ at $18^{\circ} \mathrm{C}$ and then harvested by centrifuging at $10,000 \times \mathrm{rpm}$ for $20 \mathrm{~min}$ at $4^{\circ} \mathrm{C}$. The cells were washed twice with $50 \mathrm{mM}$ sodium phosphate buffer ( $\mathrm{pH} 7.0,5 \mathrm{mM}$ ethylenediaminetetraacetic acid [EDTA], and 1\% Triton X-100) and then suspended in $50 \mathrm{mM}$ sodium phosphate buffer $(\mathrm{pH}$ 7.0). The cells were disrupted by ultrasonication (Vibracell; Sonics \& Materials, Newtown, CT, USA) and the intact cells and debris were removed by centrifugation at $12,000 \times \mathrm{rpm}$ for $20 \mathrm{~min}$ at $4^{\circ} \mathrm{C}$. The GST-tagged fusion protein was purified by GST-bind agarose resin (Elpisbiotech Co., Daejeon, Korea). The GST tag was removed from the GST-bind agarose resin after being incubated with thrombin. The homogeneity of the protein was assessed by $10 \%$ sodium dodecyl sulfate polyacrylamide gel electrophoresis (SDS-PAGE) and EZ-Gel staining solution (Daeillab Co., Seoul, Korea).

\section{Enzyme characterization and determination of ki- netic parameters}

The specific activity of purified $\mathrm{BglF} 3$ was determined by using $p$-nitrophenyl- $\beta$-D-glucopyranoside (PNPG) as substrate in $50 \mathrm{mM}$ sodium phosphate buffer ( $\mathrm{pH}$ 6.0) at $37^{\circ} \mathrm{C}$. The release of $p$-nitrophenol was immediately measured using a microplate reader at $405 \mathrm{~nm}$ (Model 680; Bio-Rad, Hercules, CA, USA). One unit of activity was defined as the amount of protein required to generate $1 \mu \mathrm{mol}$ of $p$-nitrophenol per minute. To check the optimum condition for the specific enzyme activity, $\mathrm{pH}$, temperature, metals and chemical reagents were investigated as previously described [17]. Substrate preference was examined by using chromogenic $o$-nitrophenyl (ONP) and $p$-nitrophenyl (PNP). Kinetic studies were performed with freshly purified enzyme using PNPG and $\mathrm{Rb} 1$ at concentrations ranging from $0.1 \mathrm{mM}$ to $5 \mathrm{mM}$. All enzyme assays were performed with triplicate. The 
parameters $\left(K_{m}\right.$ and $\left.V_{\max }\right)$ were determined as described by Wang et al. [3].

\section{Enzymatic hydrolysis of ginsenosides}

To investigate the biotransformation ability of recombinant $\beta$-glucosidase, $\mathrm{BglF} 3,9$ different ginsenosides (Rb1, Rb2, Rc, Rd, Gypenoside XVII, Rg3(S), Re, Rg1, and F2) were evaluated as substrates. The initial biotransformation experiments using ginsenoside $\mathrm{Rb}_{1}$ as the substrate revealed that GST fused with BglF3 did not affect the activities of BglF3. Each ginsenoside was reacted with fused protein solution $(0.2 \mathrm{mg} / \mathrm{mL}$ in $50 \mathrm{mM}$ sodium phosphate buffer, $\mathrm{pH} 6.0)$ with same ratio $(1: 1, \mathrm{v} /$ v) at $37^{\circ} \mathrm{C}$. Also, the hydrolyzing capacity of $\mathrm{BglF} 3(0.2$ $\mathrm{mg} / \mathrm{mL}$ ) was determined by using $1.0,2.5$, and $5.0 \mathrm{mg} /$ $\mathrm{mL} \mathrm{Rb1}$ as a substrate in $50 \mathrm{mM}$ sodium phosphate buffer (pH 6.0) at $37^{\circ} \mathrm{C}$. Samples were withdrawn at regular intervals. An equal volume of water-saturated $n$-butanol was added to stop the reaction, and the reactant present in the $n$-butanol fraction was analyzed by TLC after pretreatment.

\section{Analysis of ginsenosides by thin-layer chromatog- raphy}

TLC was performed using $60 \mathrm{~F}_{254}$ silica gel plates (Merck, Darmstadt, Germany) with $\mathrm{CHCl}_{3}-\mathrm{CH}_{3} \mathrm{OH}-\mathrm{H}_{2} \mathrm{O}$ (65:35:10, $\mathrm{v} / \mathrm{v}$, lower phase) in solvent system. The spots on the TLC plates were detected through spraying with $10 \%$ (vol $/ \mathrm{vol}$ ) $\mathrm{H}_{2} \mathrm{SO}_{4}$, followed by heating at $110^{\circ} \mathrm{C}$ for $5 \mathrm{~min}$.

\section{RESULTS AND DISCUSSION}

\section{Cloning, expression, and purification of recombi- nant BgIF3}

The $\beta$-glucosidase gene consisting of $2,235 \mathrm{bp}$ encoding 744 amino acids, which have homology to the protein domain of glycoside hydrolase family 3 , was amplified by PCR and then inserted into the pGEX 4T-1 vector. The GST-BglF3 fusion gene was expressed in E. coli BL21 (DE3) followed by the induction of 0.1 $\mathrm{mM}$ IPTG and incubated at $18^{\circ} \mathrm{C}$ for $24 \mathrm{~h}$. The GST$\mathrm{BglF} 3$ fusion protein was purified by GST-bind agarose resin and then the GST tag was removed by thrombin at room temperature during a $12 \mathrm{~h}$ incubation period. The predictive molecular mass $(81.8 \mathrm{KDa})$ of the $\mathrm{BglF} 3$ was determined by SDS-PAGE (Fig. 1).

\section{Enzyme characterization}

BglF3 was active over a broad $\mathrm{pH}$ range $(\mathrm{pH} 4.0$ to 9.0 ) at $37^{\circ} \mathrm{C}$. The optimum $\mathrm{pH}$ was $\mathrm{pH} 6.0$ in sodium

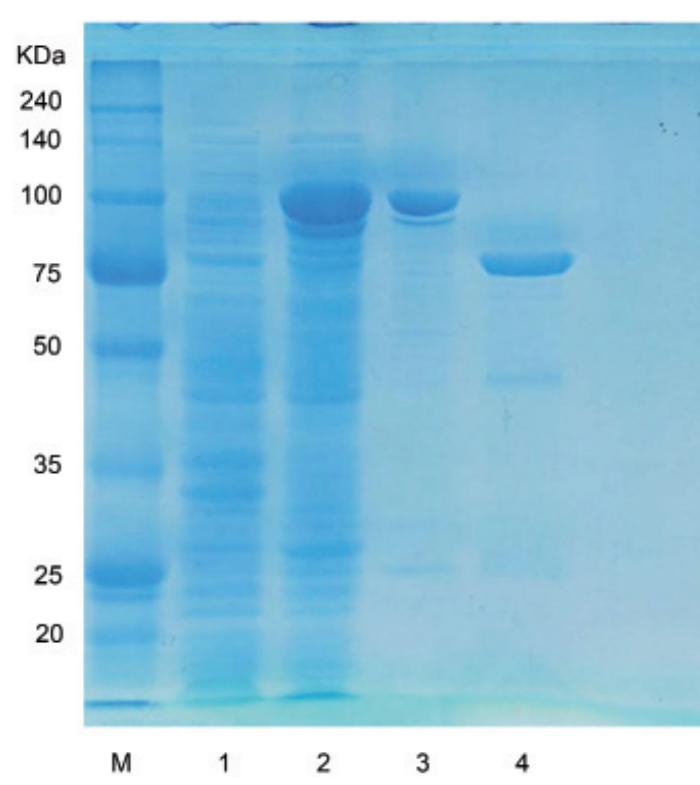

Fig. 1. Sodium dodecyl sulfate polyacrylamide gel electrophoresis analysis of purified BgIF3. 1, uninduced crude extract; 2 , induced crude extract; 3 , glutathione S-transferase (GST)-BgIF3 enzyme fraction after purification by GST-bind agarose resin; 4, cleavage of GSTBglF3 by thrombin. KDa, kilodalton; M, marker.

phosphate buffer (Fig. 2A). The enzyme activity retained more than $80 \%$ of its optimal activity from $\mathrm{pH} 5.0$ to 8.0, while above $\mathrm{pH} 10.0$ enzyme activity decreased upto $95 \%$ and at $\mathrm{pH} 4.0$ the enzyme activity decreased to $30 \%$. The $\beta$-glucosidase from Paecilomyces Bainier sp. 229 [18], Thermus caldophilus [19], and Microbacterium esteraromaticum [20] had optima at $\mathrm{pH} 3.5,5.0$, and 7.0, respectively. The optimal temperature for $\mathrm{BglF} 3$ activity was $37^{\circ} \mathrm{C}$ and the enzyme was stable at lower than $37^{\circ} \mathrm{C}$. The enzyme lost $35 \%$ of its activity at $45^{\circ} \mathrm{C}$, while no thermostability was determined at $55^{\circ} \mathrm{C}$ (Fig. 2B). However, the purified $\beta$-glucosidase from Paecilomys Bainier sp. 229 [18], T. caldophilus [19], and Sulfolobus solfataricus [21] had the optimal temperatures of $55^{\circ} \mathrm{C}$, $75^{\circ} \mathrm{C}$, and $90^{\circ} \mathrm{C}$, respectively.

The effects of metal ions, EDTA, $\beta$-mercaptoethanol, and sodium dodecyl-sulfate (SDS) on BglF3 activity were investigated (Table 1). BglF3 activity was not affected by dithiothreitol or $\beta$-mercaptoethanol, which is a well-known thiol group inhibitor. $\mathrm{Na}^{+}, \mathrm{K}^{+}$, or $\mathrm{Mg}^{2+}$ had positive effects on the activity of the enzyme while the enzyme activity was inhibited in the presence of both $1 \mathrm{mM}$ and $10 \mathrm{mM} \mathrm{Mn}{ }^{2+}, \mathrm{Co}^{2+}, \mathrm{Zn}^{2+}, \mathrm{Ca}^{2+}, \mathrm{Cu}^{2+}$, or $\mathrm{Hg}^{2+}$. The chelating agents EDTA and SDS also inhibited BglF3 activity.

The substrate specificity of BglF3 was tested using $2.0 \mathrm{mM}$ of PNP and ONP-glycosides with $\alpha$ and $\beta$ configurations (total 17 kinds), as reported previously 


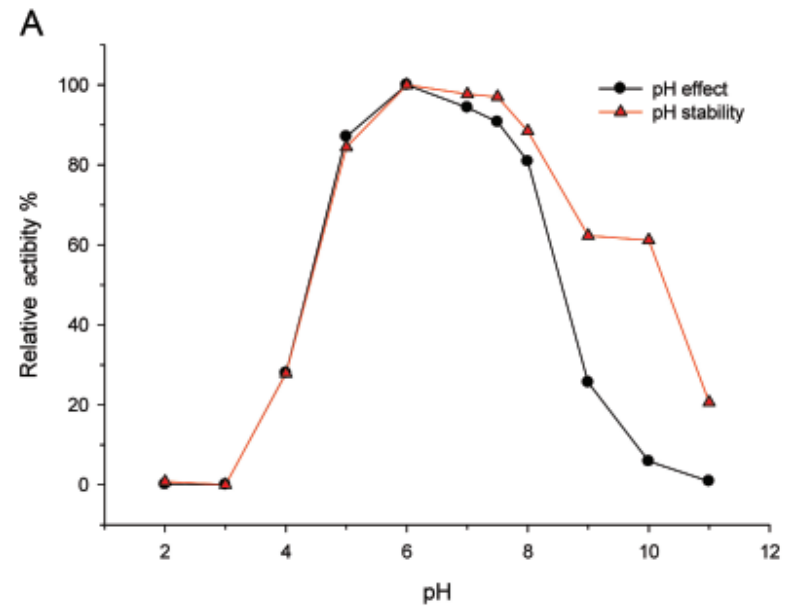

в

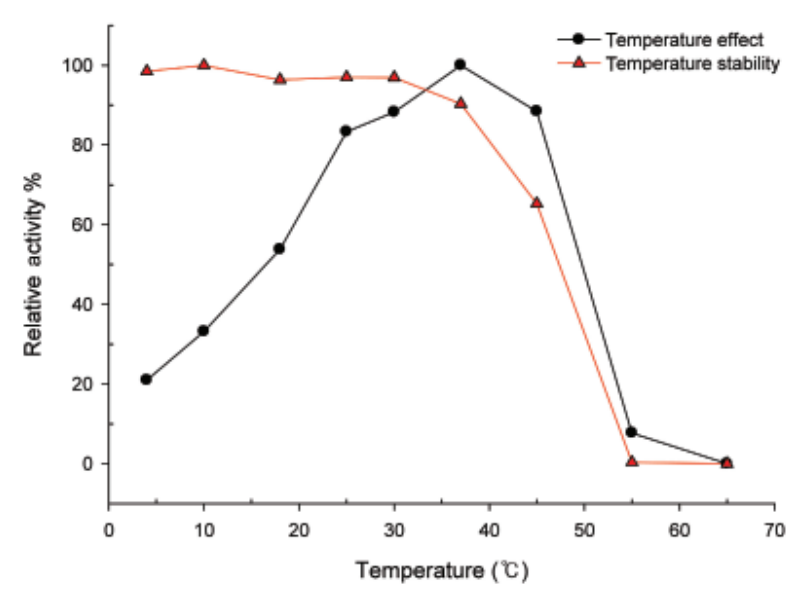

Fig. 2. Effects of $\mathrm{pH}(\mathrm{A})$ and temperature $(\mathrm{B})$ on the stability and activity of BgIF3.

Table 1. Effects of metal ions and chemical agents on the activity of purified BglF3

\begin{tabular}{lcc}
\hline \multirow{2}{*}{ Metal ions or reagents } & \multicolumn{2}{c}{ Relative activity $\pm \mathrm{SD}(\%)$} \\
\cline { 2 - 3 } & $1 \mathrm{mM}$ & $10 \mathrm{mM}$ \\
\hline $\mathrm{NaCl}$ & $143.9 \pm 1.6$ & $108.2 \pm 1.5$ \\
$\mathrm{KCl}$ & $128.2 \pm 3.5$ & $110.2 \pm 1.6$ \\
$\mathrm{MgCl}_{2}$ & $152.6 \pm 3.3$ & $112.5 \pm 3.4$ \\
$\mathrm{MnCl}_{2}$ & $53.3 \pm 1.0$ & $39.7 \pm 2.4$ \\
$\mathrm{CoCl}_{2}$ & $58.8 \pm 3.5$ & $44.3 \pm 2.7$ \\
$\mathrm{ZnCl}_{2}$ & $4.7 \pm 1.7$ & $2.9 \pm 2.5$ \\
$\mathrm{CaCl}_{2}$ & $92.5 \pm 2.6$ & $81.0 \pm 1.9$ \\
$\mathrm{CuCl}_{2}$ & $6.3 \pm 1.4$ & $6.0 \pm 2.0$ \\
$\mathrm{HgCl}_{2}$ & 0 & 0 \\
$\mathrm{SDS}$ & $39.9 \pm 3.2$ & $1.98 \pm 1.7$ \\
EDTA & $76.4 \pm 2.7$ & $68.9 \pm 3.7$ \\
$\beta$-mercaptoethanol & $93.8 \pm 1.7$ & $91.9 \pm 1.8$ \\
DTT & $96.0 \pm 4.1$ & $97.9 \pm 3.4$ \\
Control & $100.0 \pm 2.6$ & $100.0 \pm 1.5$ \\
\hline
\end{tabular}

SDS, sodium dodecyl-sulfate; EDTA, ethylenediaminetetraacetic acid; DTT, dithiothreitol.
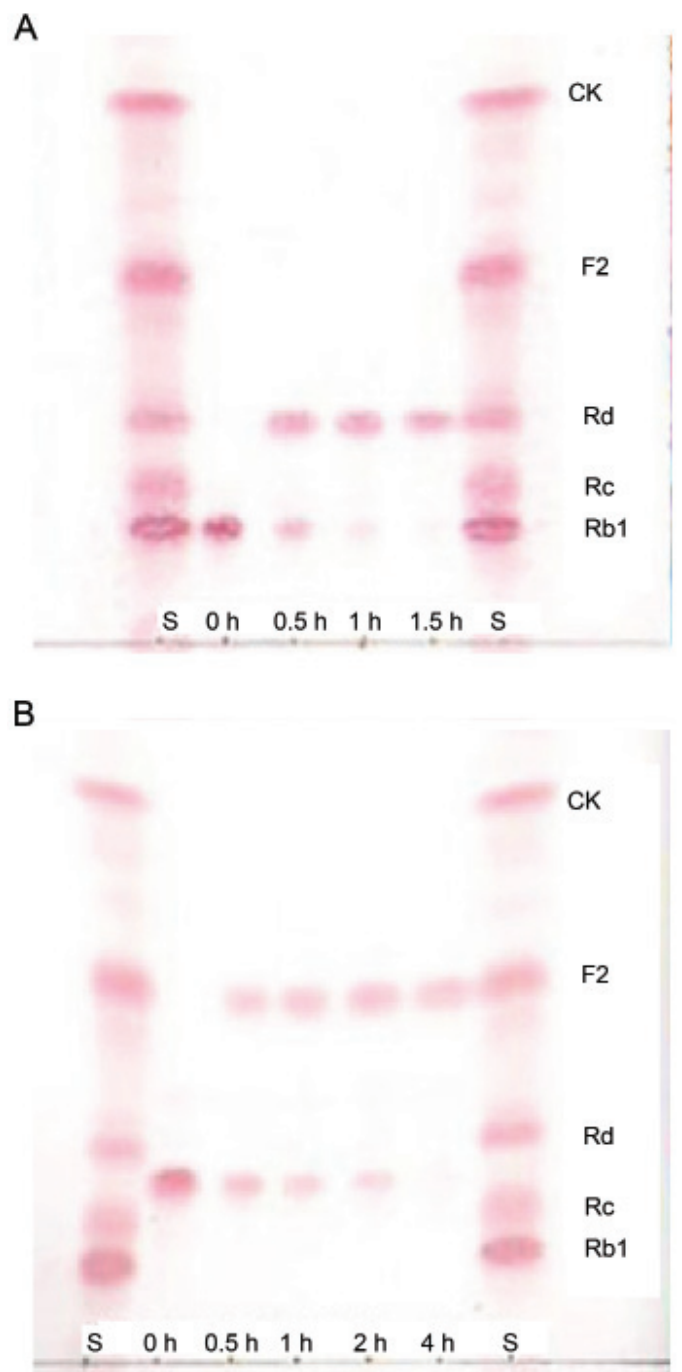

Fig. 3. TLC analyses of biotransformation of ginsenoside $R b 1$ (A) and gypenoside XVII (B) by recombinant BgIF3. S, saponin standards; CK, compound K.

$[7,17]$. BglF3 was maximally active against PNP- $\beta$-Dglucopyranoside, followed by ONP- $\beta$-D-glucopyranoside (53.2\% compared to PNP- $\beta$-D-glucopyranoside), and other substrates were not hydrolyzed. This explained why BglF3 did not have catalytic activity against ginsenoside Rb2 and Rc, which had an outer arabinose moiety at the C-20 position of aglycon. The kinetic parameters for recombinant BglF3 had apparent $K_{m}$ values of $0.91 \pm 0.02$ and $2.84 \pm 0.05 \mathrm{mM}$ and $V_{\max }$ values of $5.75 \pm 0.12$ and $0.71 \pm 0.01 \mu \mathrm{mol} \cdot \mathrm{min}^{-1} \cdot \mathrm{mg}$ of protein $^{-1}$ against $p$-nitrophenyl- $\beta$-D-glucopyranoside and $\mathrm{Rb} 1$, respectively.

\section{Biotransformation of ginsenosides}

For a thorough investigation of ginsenoside transfor- 

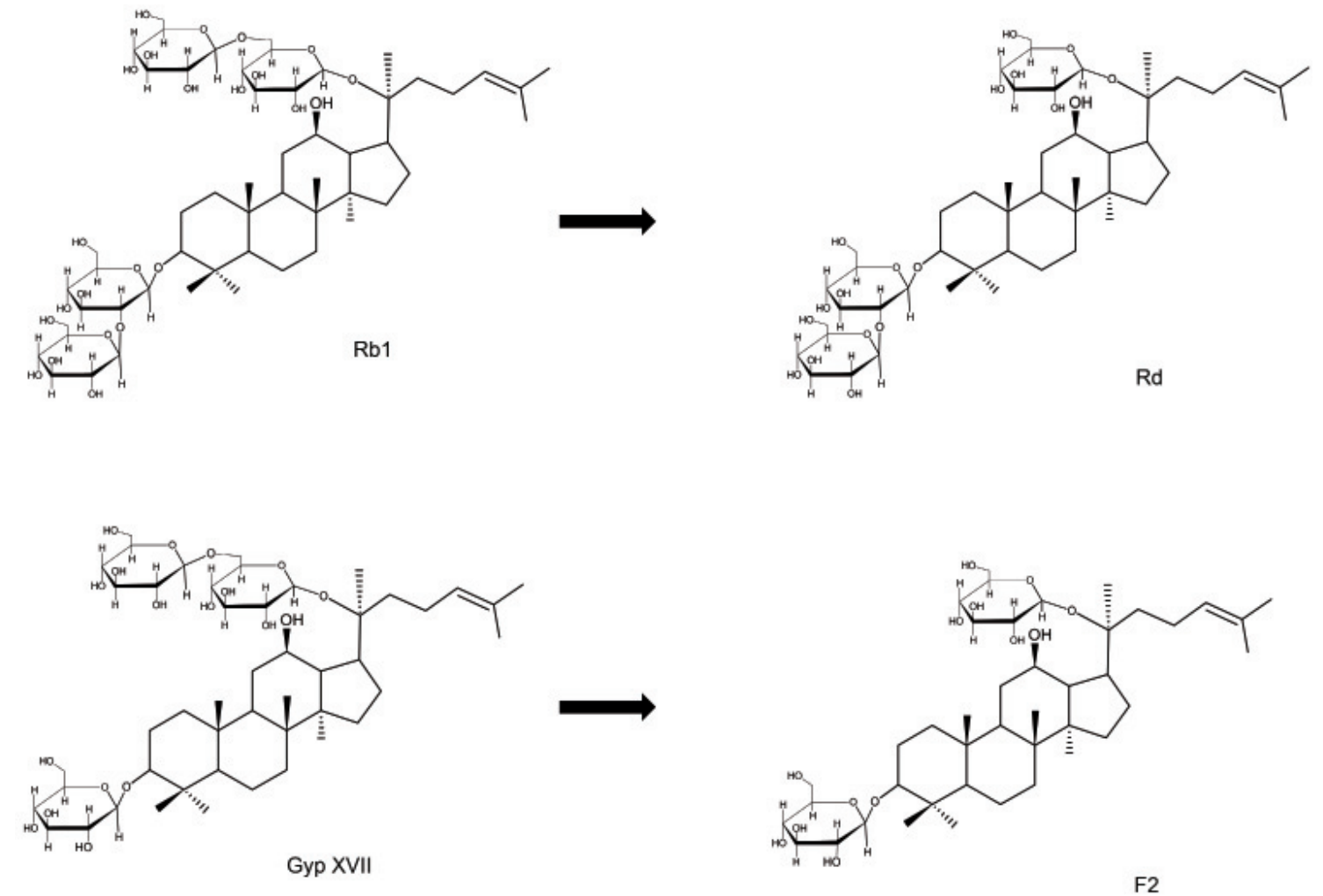

Fig. 4. Biotransformation pathways from ginsenoside Rb1 and gypenoside XVII to ginsenosides Rd and F2 by recombinant BglF3, respectively.

mation by recombinant $\mathrm{BglF} 3,9$ ginsenosides (Rb1, $\mathrm{Rb} 2, \mathrm{Rc}, \mathrm{Rd}$, gypenoside XVII, Rg3(S), Re, Rg1, and F2) were used as substrates and recombinant BglF3 could hydrolyze only ginsenoside $\mathrm{Rb} 1$ and gypenoside $\mathrm{XVII}$. The hydrolysates of ginsenoside Rb1 and gypenoside XVII were examined at regular intervals by TLC. Ginsenoside Rb1 (1 mg/mL) and gypenoside XVII (1 $\mathrm{mg} / \mathrm{mL}$ ) were completely converted into ginsenosides $\mathrm{Rd}$ and $\mathrm{F} 2$ after $1.5 \mathrm{~h}$ and $4 \mathrm{~h}$, respectively, and no further production occurred during longer reaction time (Fig. $3)$. This conversion speed was faster than that obtained with the usage of crude enzymes extracts from Paecilomyces sp. 229-7 [22] and Bifidobacterium sp. SH5 [23], which converted $1 \mathrm{mg} / \mathrm{mL}$ of ginsenoside $\mathrm{Rb} 1$ to $\mathrm{Rd}$ within $24 \mathrm{~h}$. These results indicated that BglF3 showed substrate specificity for ginsenoside $\mathrm{Rb} 1$ and gypenoside XVII, which had glucose moieties at the C-3 and C-20 positions, and showed specific affinity to only the outer C-20 glucose moiety (Fig. 4). To evaluate the usage of BglF3 at an industrial scale, a high concentration of ginsenosides $\mathrm{Rb}_{1}$ was used as the substrate. $\mathrm{BglF} 3$ could wholly hydrolyze 2.5 and $5.0 \mathrm{mg} / \mathrm{mL}$ of the ginsenosides Rb1 into Rd within 20 and 72 h, respectively (Fig. 5). Thus, it would be a very practical tool to prepare a large amount of ginsenoside Rd with high-yield if a purified

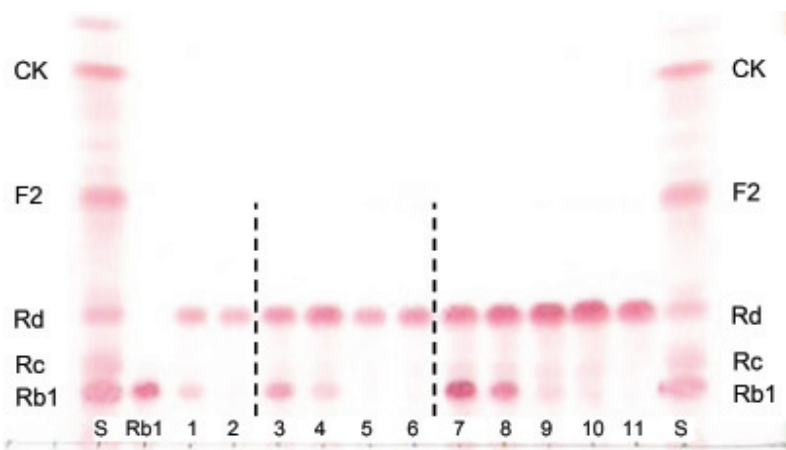

Fig. 5. TLC analyses of ginsenoside Rd production from 1.0, 2.5, and $5.0 \mathrm{mg} / \mathrm{mL}$ ginsenoside $\mathrm{Rb} 1$ by recombinant BglF3. Reaction mixture of $1.0 \mathrm{mg} / \mathrm{mL} \mathrm{Rb} 1: 1,2$; reaction mixture of $2.5 \mathrm{mg} / \mathrm{mL} \mathrm{Rb} 1$ : $3,4,5,6$; reaction mixture of $5.0 \mathrm{mg} / \mathrm{mL} \mathrm{Rb} 1: 7,8,9,10,11$; reaction time: 1, 0.5 h; 2, 1.5 h; 3, 1 h; 4, 3 h; 5, 12 h; 6,20 h; 7, 1 h; 8, 3 h; 9 , $20 \mathrm{~h} ; 10,48 \mathrm{~h} ; 11,72$ h. S, saponin standards; CK, compound K.

ginsenoside mixture (Rb1, Rc, and Rd) is used as the substrate.

Theoretically, $\beta$-glucosidase can hydrolyze the outer and inner glucoses attached to ginsenosides at the C-3 and C-20 positions in various transformation pathways. With regard to glycoside hydrolase family 3 , where BglF3 is included, there have been several reports on ginsenoside conversion. For example, Bgp A derived from Terrabacter ginsenosidimutans Gsoil $3082^{\mathrm{T}}$ prefer- 
entially hydrolyzed the outer glucose moiety at the C-3 position followed by the inner glucose moiety to make gypenoside XVII and gypenoside LXXV and further into compound $\mathrm{K}$ by hydrolyzing the $\mathrm{C}-20$ glucose moiety [17]. Bgp1 derived from M. esteraromaticum preferentially hydrolyzed both the outer and inner glucose moieties at the $\mathrm{C}-20$ position until ginsenoside $\mathrm{Rg} 3$ was produced finally [24]. The other enzyme, $\beta$-glucosidase from Cladosporium cladosporioides, converted gypenoside XVII into ginsenoside F2 by hydrolyzing the outer glucose at the C-20 position and further into compound $\mathrm{K}$ by hydrolyzing the $\mathrm{C}-3$ glucose moiety [25]. However, in this study, BglF3 could selectively hydrolyze only one outer glucose at the C-20 position for the major ginsenoside Rb1 and gypenoside XVII.

In conclusion, we have constructed recombinant $\beta$-glucosidase (BglF3) from F. johnsoniae KACC $11414^{\mathrm{T}}$ for biotransformation of ginsenoside Rb1 and gypenoside XVII to more pharmacologically active ginsenosides $\mathrm{Rd}$ and F2, respectively, by selectively hydrolyzing their outer glucose moiety at the C-20 position. Optimal reaction conditions for the enzyme are $37^{\circ} \mathrm{C}$ and $\mathrm{pH} \mathrm{6.0.} \mathrm{The}$ recombinant $\mathrm{BglF} 3$ provides effective ginsenoside $\mathrm{Rb} 1$ transformation with high productivity. Therefore, $\mathrm{BglF} 3$ would offer a shortcut to prepare ginsenosides Rd and F2 in large-scale industrial production.

\section{ACKNOWLEDGEMENTS}

This work was supported by a grant from the NextGeneration BioGreen 21 Program (no. PJ008193), Rural Development Administration, and by the Intelligent Synthetic Biology Center of Global Frontier Project funded by the Ministry of Education, Science and Technology (2011-0031967), Republic of Korea.

\section{REFERENCES}

1. Ernst E. Panax ginseng: An overview of the clinical evidence. J Ginseng Res 2010;34:259-263.

2. Kim MH, Lee YC, Choi SY, Cho CW, Rho J, Lee KW. The changes of ginsenoside patterns in red ginseng processed by organic acid impregnation pretreatment. J Ginseng Res 2011;35:497-503.

3. Wang L, Liu QM, Sung BH, An DS, Lee HG, Kim SG, Kim SC, Lee ST, Im WT. Bioconversion of ginsenosides $\mathrm{Rb} 1, \mathrm{Rb} 2$, Rc and Rd by novel $\beta$-glucosidase hydrolyzing outer 3-O glycoside from Sphingomonas sp. 2F2: cloning, expression, and enzyme characterization. J Biotechnol 2011;156:125-133.
4. Wang DM, Yu HS, Song JG, Xu YF, Jin FX. Enzyme kinetics of ginsenosidase type IV hydrolyzing 6-O-multiglycosides of protopanaxatriol type ginsenosides. Process Biochem 2012;47:133-138.

5. Tawab MA, Bahr U, Karas M, Wurglics M, Schubert-Zsilavecz M. Degradation of ginsenosides in humans after oral administration. Drug Metab Dispos 2003;31:10651071.

6. Akao T, Kida H, Kanaoka M, Hattori M, Kobashi K. Intestinal bacterial hydrolysis is required for the appearance of compound $\mathrm{K}$ in rat plasma after oral administration of ginsenoside Rb1 from Panax ginseng. J Pharm Pharmacol 1998;50:1155-1160.

7. Kim HS, Lee EH, Ko SR, Choi KJ, Park JH, Im DS. Effects of ginsenosides $\mathrm{Rg} 3$ and $\mathrm{Rh} 2$ on the proliferation of prostate cancer cells. Arch Pharm Res 2004;27:429-435.

8. Keum YS, Han SS, Chun KS, Park KK, Park JH, Lee SK, Surh YJ. Inhibitory effects of the ginsenoside Rg3 on phorbol ester-induced cyclooxygenase-2 expression, NF-kappaB activation and tumor promotion. Mutat Res 2003;523-524:75-85.

9. Kim S, Nah SY, Rhim H. Neuroprotective effects of ginseng saponins against L-type $\mathrm{Ca}^{2+}$ channel-mediated cell death in rat cortical neurons. Biochem Biophys Res Commun 2008;365:399-405.

10. Shin JY, Lee JM, Shin HS, Park SY, Yang JE, Cho SK, Yi $\mathrm{TH}$. Anti-cancer effect of ginsenoside F2 against glioblastoma multiforme in xenograft model in SD rats. J Ginseng Res 2012;36:86-92.

11. Guan YY, Zhou JG, Zhang Z, Wang GL, Cai BX, Hong L, Qiu QY, He H. Ginsenoside-Rd from Panax notoginseng blocks $\mathrm{Ca}^{2+}$ influx through receptor- and store-operated $\mathrm{Ca}^{2+}$ channels in vascular smooth muscle cells. Eur $\mathrm{J}$ Pharmacol 2006;548:129-136.

12. Lee JK, Choi SS, Lee HK, Han KJ, Han EJ, Suh HW. Effects of ginsenoside Rd and decursinol on the neurotoxic responses induced by kainic acid in mice. Planta Med 2003;69:230-234.

13. Yang ZG, Sun HX, Ye YP. Ginsenoside Rd from Panax notoginseng is cytotoxic towards HeLa cancer cells and induces apoptosis. Chem Biodivers 2006;3:187-197.

14. Cheng LQ, Na JR, Kim MK, Bang MH, Yang DC. Microbial conversion of ginsenoside $\mathrm{Rb} 1$ to minor ginsenoside F2 and gypenoside XVII by Intrasporangium sp. GS603 isolated from soil. J Microbiol Biotechnol 2007;17:19371943.

15. Park CS, Yoo MH, Noh KH, Oh DK. Biotransformation of ginsenosides by hydrolyzing the sugar moieties of ginsenosides using microbial glycosidases. Appl Microbiol Biotechnol 2010;87:9-19. 
16. Kim BN, Yeom SJ, Kim YS, Oh DK. Characterization of a $\beta$-glucosidase from Sulfolobus solfataricus for isoflavone glycosides. Biotechnol Lett 2012;34:125-129.

17. An DS, Cui CH, Lee HG, Wang L, Kim SC, Lee ST, Jin F, Yu H, Chin YW, Lee HK et al. Identification and characterization of a novel Terrabacter ginsenosidimutans sp. nov. beta-glucosidase that transforms ginsenoside $\mathrm{Rb} 1$ into the rare gypenosides XVII and LXXV. Appl Environ Microbiol 2010;76:5827-5836.

18. Yan Q, Zhou W, Li X, Feng M, Zhou P. Purification method improvement and characterization of a novel ginsenoside-hydrolyzing beta-glucosidase from Paecilomyces Bainier sp. 229. Biosci Biotechnol Biochem 2008;72:352-359.

19. Son JW, Kim HJ, Oh DK. Ginsenoside Rd production from the major ginsenoside Rb1 by beta-glucosidase from Thermus caldophilus. Biotechnol Lett 2008;30:713-716.

20. Quan LH, Min JW, Sathiyamoorthy S, Yang DU, Kim YJ, Yang DC. Biotransformation of ginsenosides Re and $\mathrm{Rg} 1$ into ginsenosides $\mathrm{Rg} 2$ and Rh1 by recombinant $\beta$-glucosidase. Biotechnol Lett 2012;34:913-917.
21. Noh KH, Son JW, Kim HJ, Oh DK. Ginsenoside compound $\mathrm{K}$ production from ginseng root extract by a thermostable beta-glycosidase from Sulfolobus solfataricus. Biosci Biotechnol Biochem 2009;73:316-321.

22. Ye L, Zhou CQ, Zhou W, Zhou P, Chen DF, Liu XH, Shi $\mathrm{XL}$, Feng MQ. Biotransformation of ginsenoside Rb1 to ginsenoside Rd by highly substrate-tolerant Paecilomyces Bainier 229-7. Bioresour Technol 2010;101:7872-7876.

23. Chi H, Ji GE. Transformation of ginsenosides Rb1 and Re from Panax ginseng by food microorganisms. Biotechnol Lett 2005;27:765-771.

24. Quan LH, Min JW, Yang DU, Kim YJ, Yang DC. Enzymatic biotransformation of ginsenoside $\mathrm{Rb} 1$ to $20(S)-\mathrm{Rg} 3$ by recombinant $\beta$-glucosidase from Microbacterium esteraromaticum. Appl Microbiol Biotechnol 2012;94:377384.

25. Wu L, Jin Y, Yin C, Bai L. Co-transformation of Panax major ginsenosides Rb1 and Rg1 to minor ginsenosides $\mathrm{C}-\mathrm{K}$ and $\mathrm{F} 1$ by Cladosporium cladosporioides. J Ind Microbiol Biotechnol 2012;39:521-527. 